\title{
Current Mode based Communication System
}

\author{
Prof. Dr. Uday Pandit Khot ${ }^{1}$, N.A. Bhagat ${ }^{2}$ \\ Electronics and Telecommunication Department, St. Francis Institute of Technology, Borivali (w), Mumbai, India ${ }^{1}$ \\ Electronics Department, Sardar Patel Institute of Technology, Andheri (w), Mumbai, India ${ }^{2}$
}

\begin{abstract}
This paper focuses on the various advantages of current mode circuits over the widely used voltage mode circuits in communication system. The individual blocks of a basic communication system are designed in voltage mode and the circuits are then converted into their equivalent voltage mode. Conclusions are drawn based on the various responses observed in both the modes. The existing available VM devices/circuits for communication systems are having restricted band width, and size constraints. Using such devices, the supply voltage level cannot go below minimum value (as low as 1.2 volts) and also there is problem of power dissipation due to size constraints. The size cannot be further reduced as the power dissipation problem may damage the device. As compared to VM building blocks, the current mode (CM) building blocks can generally operate with low voltages and have higher bandwidth and slew rate. The validity of the information and results are based on the circuits simulated in PSPICE.
\end{abstract}

Keywords: Voltage Mode, Current Mode, Current Feedback Amplifiers, Operational Amplifiers (OP-Amps), GainBandwidth product

\section{INTRODUCTION}

In a CM building block, the output is controlled by the input current. The analog circuits using such building blocks have simple topologies and are suitable for the integrated circuit (IC) technology [1]. Due to the availability of the CM building blocks, the synthesis of analog circuits using these building blocks have received renewed attention [2]. The need of high speed, high performance, low power circuits because of the advent of the portable electronic and communication systems and difficulties faced in achieving that in today's scenario are known [3]. Current mode circuits may be the best suited candidates for the above. Therefore, there is a need to explore the current-mode techniques which may help in designing the circuits with gain bandwidth independency and operating on low voltages for communication systems. It is needed to develop the current-mode techniques and current-mode devices/circuits for communication systems. Thus in this paper we have shown a system for communication application(s) with increased bandwidth, smaller size, and reduced power consumption, using CM device(s)/technique(s) to achieve the above goals. We have simulated the communication system which uses the voltage mode technology and their performance characteristics. The same circuits then implemented using the current mode circuits and compared the characteristics.

The most simple and useful current mode circuits are the current conveyors [4]. They have wide applications in signal processing areas and the fields where mixed circuit (analog and digital) design is gaining importance. Voltage mode circuits that were used in the past can now be implemented using current conveyors (CM devices) [5]. Also along with the use of CM circuits it is desired to have simple design as they are expected to lead easy fabrication process and so there is effort required for designing the circuits that employ simple topologies. The use of current mode circuits will gain more and more importance as the development in portable electronics will advance. Recently, the work is going on in the area of development of CM techniques for various circuit blocks of communication systems such as filters, mixers, PLL,SAH circuits, transceivers etc [6][7]. Current Mode devices are the ones where outputs voltage and/or current are controlled by the input current. The reason to use current mode as they can have following advantages: operate with low voltages, provide higher bandwidth, provide high slew rate, and lead to simple circuit topologies [8]. The gain-bandwidth independency of CM devices can be proved as follows. Consider a simple VM op-amp based non-inverting amplifier circuit shown in Figure 1.

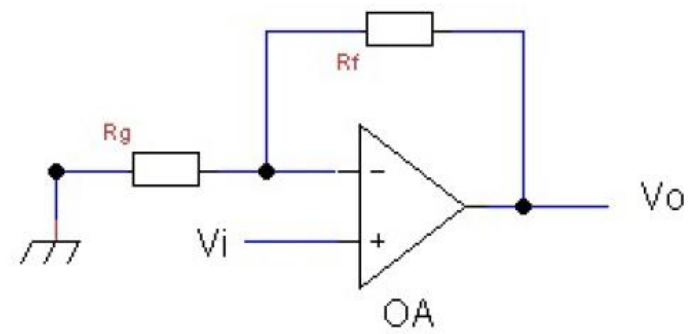

Figure 1: op-amp based non-inverting amplifier.

The analysis of the circuit leads to,

$$
\begin{gathered}
A_{V}(f)=\frac{V_{o}}{V_{i}}=\frac{G}{1+\frac{G}{A(f)}}, A_{V}(f)=\frac{V_{o}}{V_{i}}=\frac{G}{1+\frac{j f}{f_{o}}} \\
A_{c}(f) \approx \frac{G}{1+\frac{j f}{\left(\frac{A_{o} f_{o}}{G}\right)}} \text { where } G=1+\frac{R_{f}}{R_{g}} \\
B W=\frac{A_{o} f_{o}}{G}
\end{gathered}
$$

Here we can see that the gain and bandwidth are dependent on each other or rather we can say that in VM techniques the gain bandwidth product is interdependent. Therefore if we increase the gain, bandwidth reduces and vice versa. On the other hand let us consider the similar configuration which is achieved using CM device (CFA) as shown in Figure 2. Thus one can see that, in the circuits using CM 


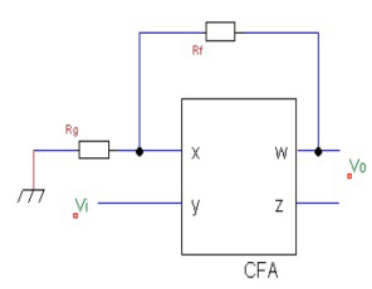

Figure 2: CFA based device

devices, the high gain and the band width can be achieved simultaneously [9]. The device may further be useful for high speed communication applications. Secondly, as the $\mathrm{CM}$ devices are operating on current input signals, the supply voltage requirement need not be as high as 1.2 volts which may help in optimizing the power dissipation with decrease in the device size.

$$
\begin{gathered}
A_{v}(f)=\frac{V_{o}}{V_{f}}=\frac{G}{1+\frac{R_{f}+G R_{x}}{Z(f)}} \\
A_{v}(f) \approx \frac{G}{1+\frac{j f}{\left[\frac{R_{T} f_{o}}{\left(R_{f}+G R_{x}\right)}\right]}} \\
B W=\left[\frac{R_{T} f_{o}}{R_{f}+G R_{x}}\right] \\
B W=\left[\frac{R_{T} f_{o}}{R_{f}}\right]
\end{gathered}
$$

Thus, we can see that in the current mode op-amp the gain and bandwidth are independent of each other.

\section{BASIC COMMUNICATION SYSTEM}

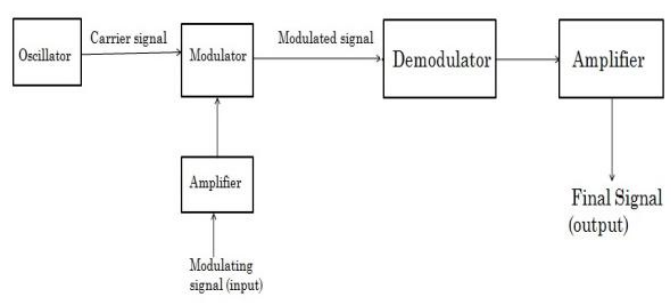

Fig 3: Block diagram of a communication system

Communication is the study of the transmission of various data through different systems. We can transfer the information from one region to another without any loss of the data. A communication system as shown in fig. 3 is a collection of network systems which includes transmitter, channel and receiver system [10]. All these components perform effectively in a good communication system. The basic blocks of the system are formed by the oscillator, amplifier, modulator and demodulator. The oscillator produces a high frequency carrier signal which is given to the modulator. The modulator block has two input signals. One is the signal coming from the oscillator and another one is the modulating signal (the input signal). The output of the modulator is called the modulated signal and this is transmitted over the channel. At the receiver end, this signal is decoded using the demodulator. An amplifier is used to amplify the attenuated signals and get the required output signals. The complete communication System shown above is developed using Voltage Mode. We have used IC LM675 for that which is VFA [11]. The same circuit is then converted into Current Mode using CFA (AD 844) [12].The performances are compared which are discussed further.

\section{CIRCUITS \& SIMULATIONS [13]}

\subsection{Amplifier in voltage mode}

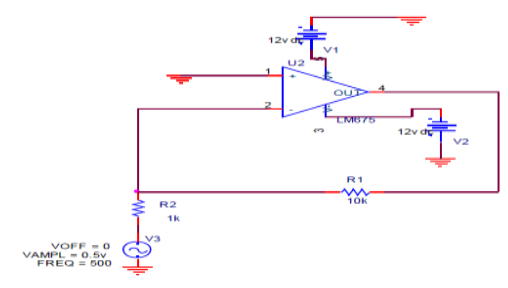

Fig 4: Amplifier in voltage mode

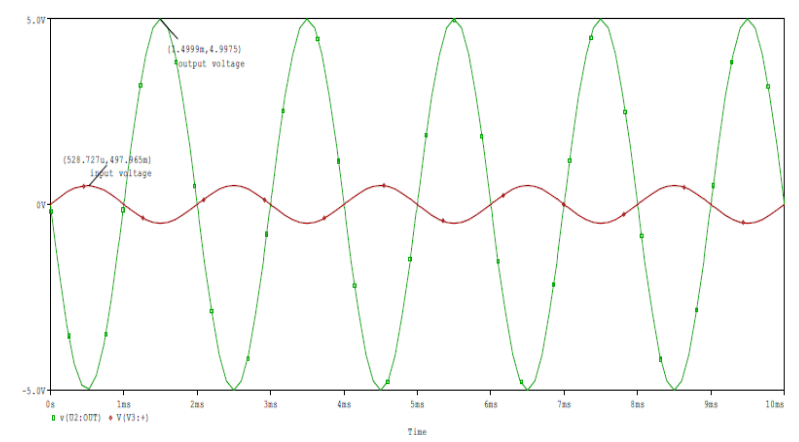

Fig 5: Output File for amplifier in VM

Non-inverting Voltage mode amplifier as shown in fig.4 is designed using Voltage Feedback Operational Amplifier where the gain provided by the circuit depends upon the feedback network.

Gain $=-\mathrm{RF} / \mathrm{RI}=-\mathrm{R} 1 / \mathrm{R} 2=-10 \mathrm{~K} / 1 \mathrm{~K}=10$

As we can see from the above waveform in fig 5:

I/p voltage: $0.5 \mathrm{~V}$

$\mathrm{O} / \mathrm{p}$ voltage: $5 \mathrm{~V}$

Total Power Dissipation: 2.09E-01 WATTS

Thus the above simulation successfully gives the voltage gain of 10 .

\subsection{Amplifier in current mode}

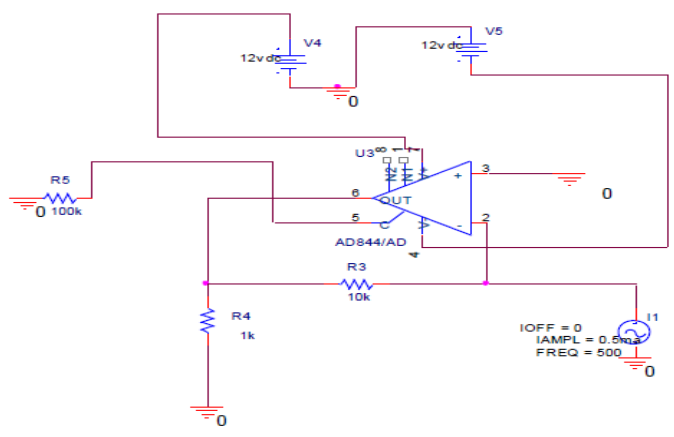

Fig 6: Amplifier in current mode 


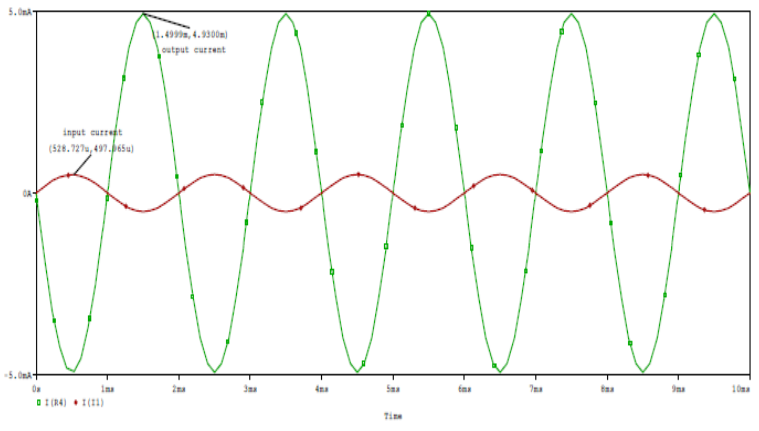

Fig 7: Waveform of amp in current mode

The circuit shown above in fig. 6 is current mode inverting amplifier and it is the converted version of the voltage mode inverting amplifier.

Gain $=-\mathrm{RF} / \mathrm{RI}=-\mathrm{R} 3 / \mathrm{R} 4=-100 \mathrm{~K} / 10 \mathrm{~K}=10$

As we can see from the above waveform in fig. 7:

I/p voltage: $0.5 \mathrm{~mA} \mathrm{O} / \mathrm{p}$ voltage: $5 \mathrm{~mA}$

Total Power Dissipation: 1.59E-01 WATTS

Thus the above simulation successfully gives the current gain of 10 .

\subsection{Voltage mode oscillator}

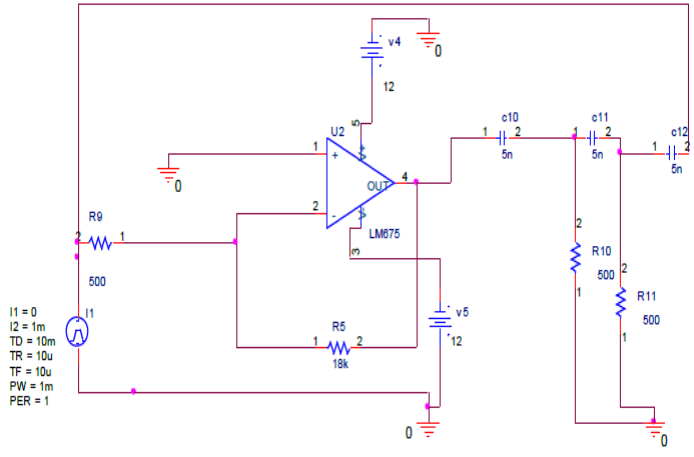

Fig 8: Voltage Mode Oscillator

It is a RC phase shift voltage mode oscillator shown in fig.8 using $3 \mathrm{RC}$ phase shift network each providing aphase shift of 60 degree.

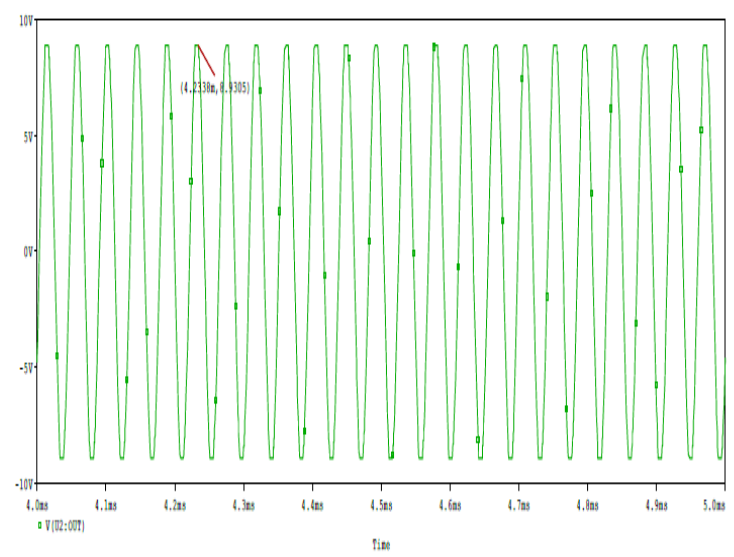

Fig 9: Output for VM oscillator

$$
\text { If } R_{9}=R_{10}=R_{1 a}=\text { RAnd }_{1}=C_{2}=C_{3}=C
$$

$$
f_{\text {oscillation }}=\frac{1}{2 \pi R C \sqrt{6}}
$$

The oscillation criteria is:

$$
\begin{gathered}
R_{f b}=29 . R \\
R=500 \Omega C=5 n F
\end{gathered}
$$

Therefore,

Calculated Frequency $=20 \mathrm{kHz}$

Simulated Output $=19.9 \mathrm{kHz}$

Total Power Dissipation=: 2.09E-01 WATTS.

Thus, Voltage mode RC Phase Shift gives the required career signal as shown in fig.9 for voltage mode communication system.

\subsection{Current Mode Oscillator}

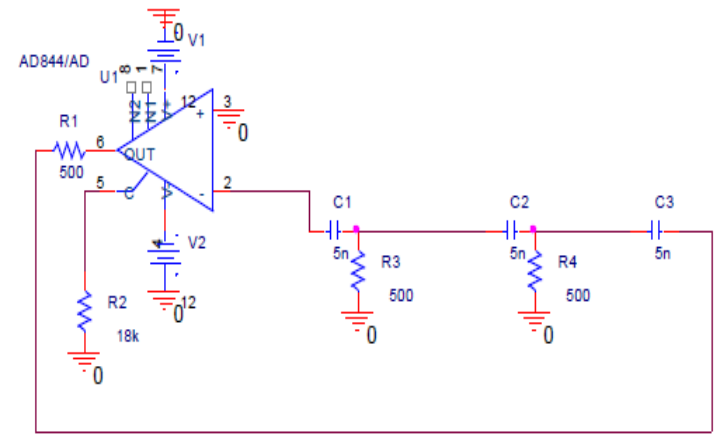

Fig 10: Current Mode RC Phase Shift Oscillator

This circuit shown in fig. 10 is current mode RC phase shift oscillator to provide a carrier signal for current mode system and it is the converted version of the respective voltage mode oscillator.

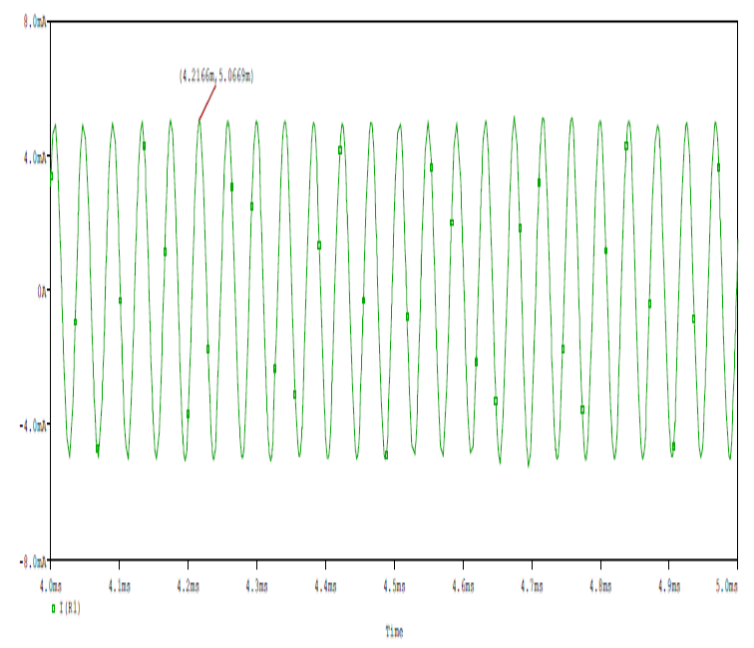

Fig 11: CM oscillator Output waveform If $R_{9}=R_{10}=R_{1 a}=$ RAnd $_{1}=C_{2}=C_{3}=C$

$$
f_{\text {oscillation }}=\frac{1}{2 \pi R C \sqrt{6}}
$$


INTERNATIONAL JOURNAL OF INNOVATIVE RESEARCH IN ELECTRICAL, ELECTRONICS, INSTRUMENTATION AND CONTROL ENGINEERING Vol. 3, Issue 3, March 2015

The oscillation criteria is:

$$
R_{f b}=29 . R
$$

$\mathrm{R}=500$ ohms $\mathrm{C}=5 \mathrm{n}$ Farads

Therefore,

Calculated Frequency $=20 \mathrm{kHz}$

Simulated Output $=20 \mathrm{kHz}$

Total Power Dissipation=1.59E-01 WATTS

Thus, Current mode RC Phase Shift gives the required career signal as shown in fig.11 for current mode communication system.

\subsection{Voltage Mode Modulator}

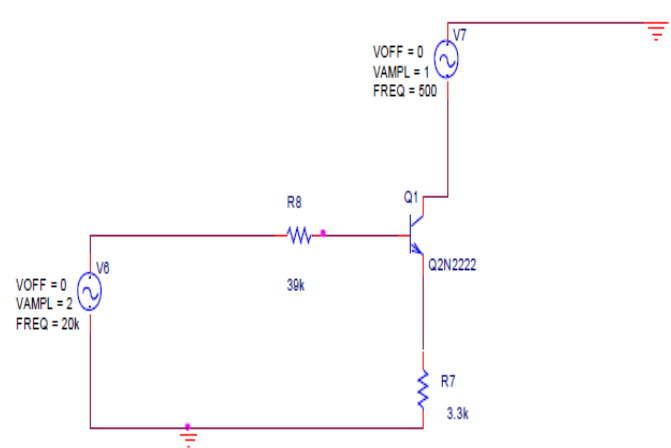

Fig 12: Modulator in voltage mode

The modulation is carried out by switching where the transistor is turned On \& Off by career signal and the output is shaped and limited by Modulating signal (information signal)

\subsection{Modulator in $\mathrm{CM}$}

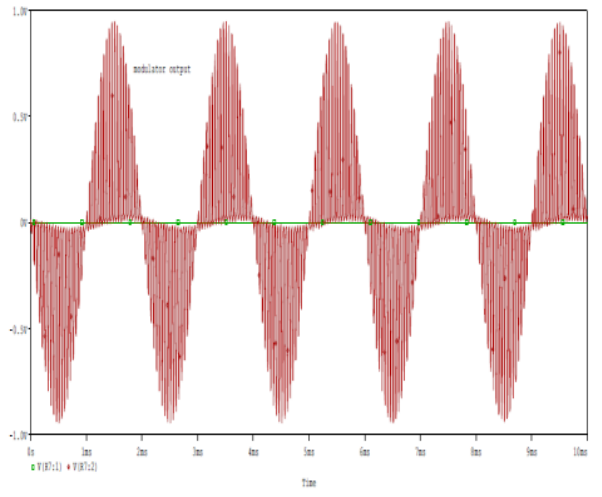

Fig 13: VM Modulator Output

Modulation is carried through a simple three terminal switch (transistor QN2222).Inputs as shown in fig. 12 are at Base we have career signal of $20 \mathrm{kHz}$, at Emitter we have Modulating Signal $500 \mathrm{~Hz}$.

At the Output Terminal i.e. Collector as shown in fig. 13 waveform is the demodulated waveform (information signal) retrieved successfully from the system.

The above waveform shows the Filter Output (Green) and the amplified version of Filtered Output (Red).The total Power Dissipation is 7.72E-01Watts.

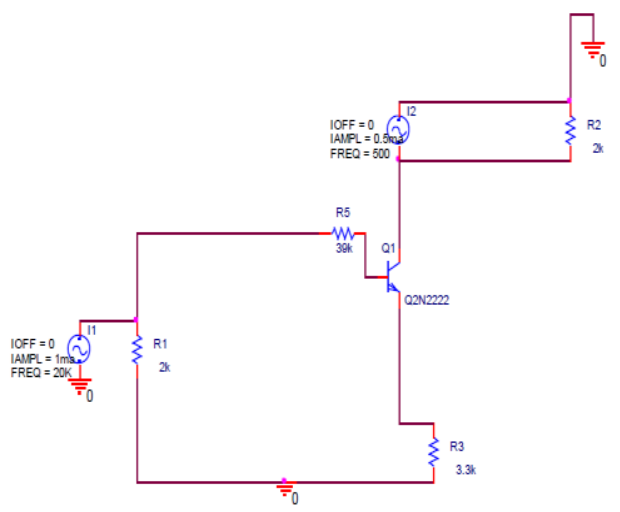

Fig 14: Current mode modulator circuit

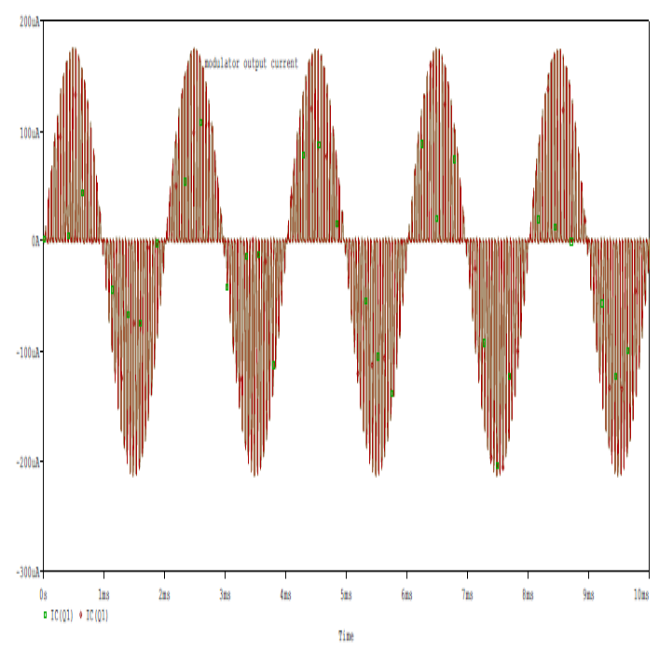

Fig 15: Waveform Current Mode modulation

Modulation is carried through a simple three terminal switch (transistor QN2222).

Inputs as shown in fig. 14 are at the Base is a Career signal of $20 \mathrm{kHz}$ and at Emitter is the Modulating Signal $500 \mathrm{~Hz}$. The output is obtained at the Collector. Modulation is carried out shown in fig. 15 by switching where the transistor is turned On \& Off by career signal and the output is shaped and limited by Modulating signal (information signal).

\subsection{Demodulator in VM}

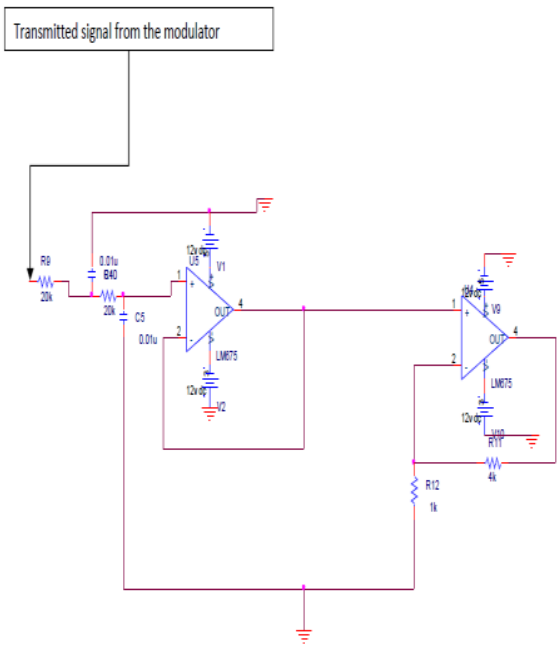

Fig 16: Demodulator block in voltage mode 
Demodulation is a process of retrieving back the The Output current is $1 \mathrm{~mA}$ (peak to peak).The above information signal (modulating signal) from the modulated waveform is the demodulated output i.e. the recovered output is shown in fig. 16. It is carried out by recovering information signal of current mode communication system the original signal shape back by passing the modulated output through an active low pass signal and then 3.9 Comparison of VM and CM amplifying the signal up to the required amplitude.

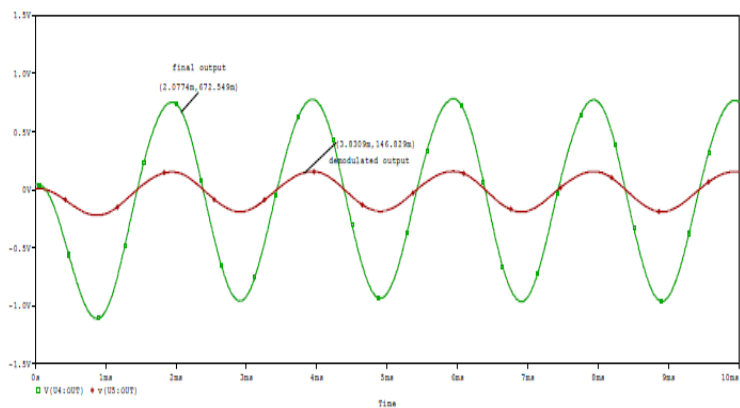

Fig 17: Output of VM demodulator

The observations are:

Outputs: V1 $($ Red $)=0.3 \mathrm{Vpp}$

V2 $($ Green $)=0.9 \mathrm{Vpp}$

Demodulator Output shown in fig. 17, the waveform shows the Filter Output (Red) and the amplified version of Filtered Output (Green).

\subsection{Current Mode Demodulator}

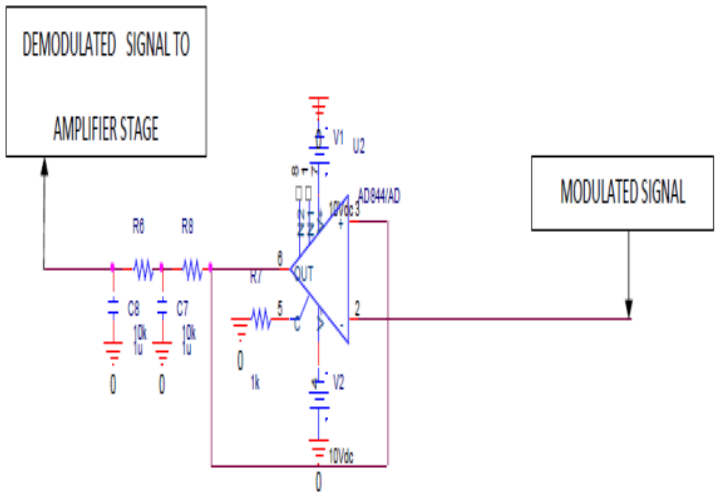

Fig 18: Current Mode Demodulator (Filter) circuit using AD844

It is a Unity Gain Buffer followed by a RC filter shown in fig. 18 to detect the modulating signal (information signal) from the modulated signal. This circuit is designed by converting the voltage mode Detector into its current mode circuit using Current Feedback Amplifier (AD844).

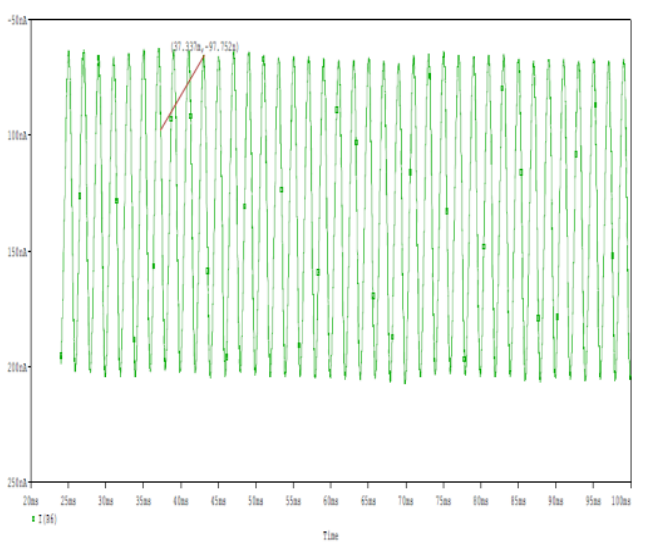

Fig 19: Output Waveform of CM
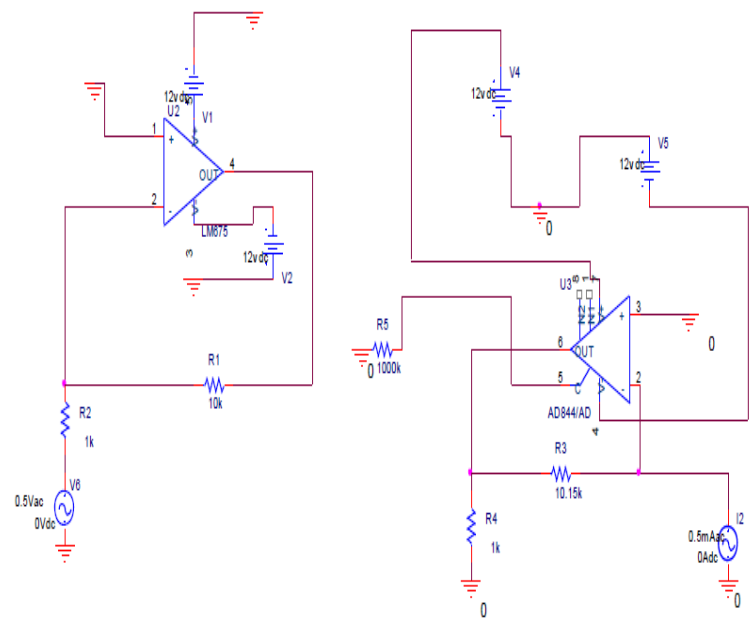

(a) Voltage mode inverting amplifier (b)Current mode inverting amplifier Fig 20: comparison of amplifiers

Voltage mode and current mode amplifiers are used at the input end of the transmitter to amplify the information signal up to the required level and also used as the final stage of Receiver to Both the circuits are tested at various frequencies to observe the output

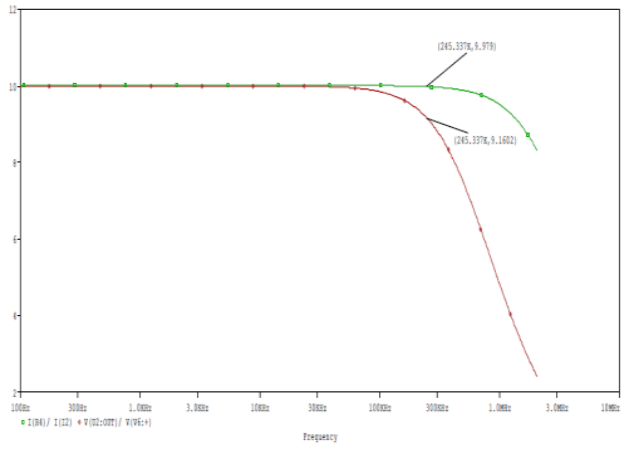

Fig 21: Output where Gain is set to 10 (Green: Current Mode, Red: Voltage mode)

As we can see from the above graph that Gain of the voltage mode amplifier using VFA reduces as the frequency of operation goes beyond $300 \mathrm{kHz}$. But, the gain of current mode amplifier remains constant even at frequencies higher than $300 \mathrm{kHz}$.

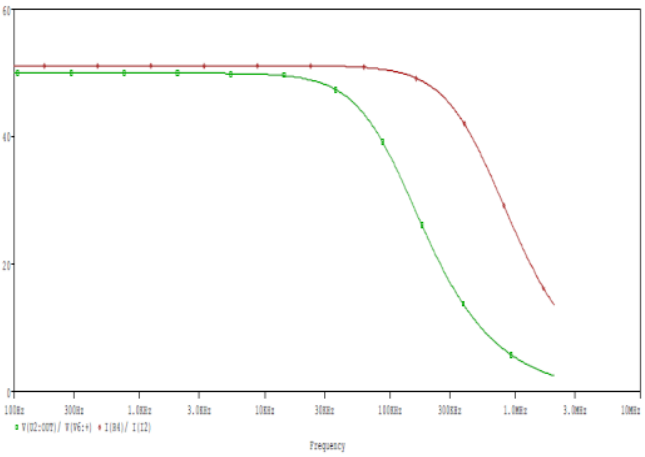

Fig 22: Simulation of amplifiers where Gain is set to 50 


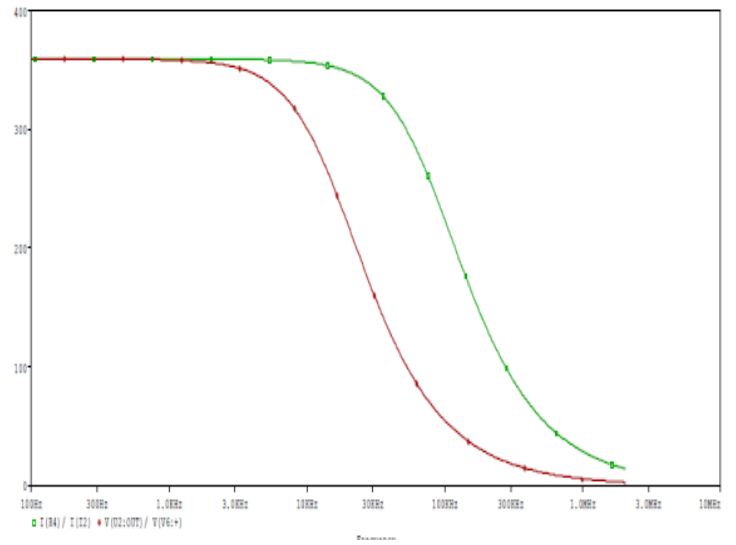

Fig 23: Simulation of amplifiers where Gain is set to 360
As observed in above graphs, as the gain increases, bandwidth of voltage mode amplifier falls more than bandwidth of current mode amplifier. But apart from this it is also been seen that bandwidth of the current mode amplifier also decreases. This contradicts the claim that in current mode voltage gain are independent. But practically it depends upon the Device to be used in current mode, its specifications, limitations etc. As observed in above graphs, as the gain increases, bandwidth of voltage mode amplifier falls more than bandwidth of current mode amplifier. But apart from this it is also been seen that bandwidth of the current mode amplifier also decreases. This contradicts the claim that in current mode voltage gain are independent. But practically it depends upon the Device to be used in current mode, its specifications, limitations etc.

\subsection{Communication System in VM}

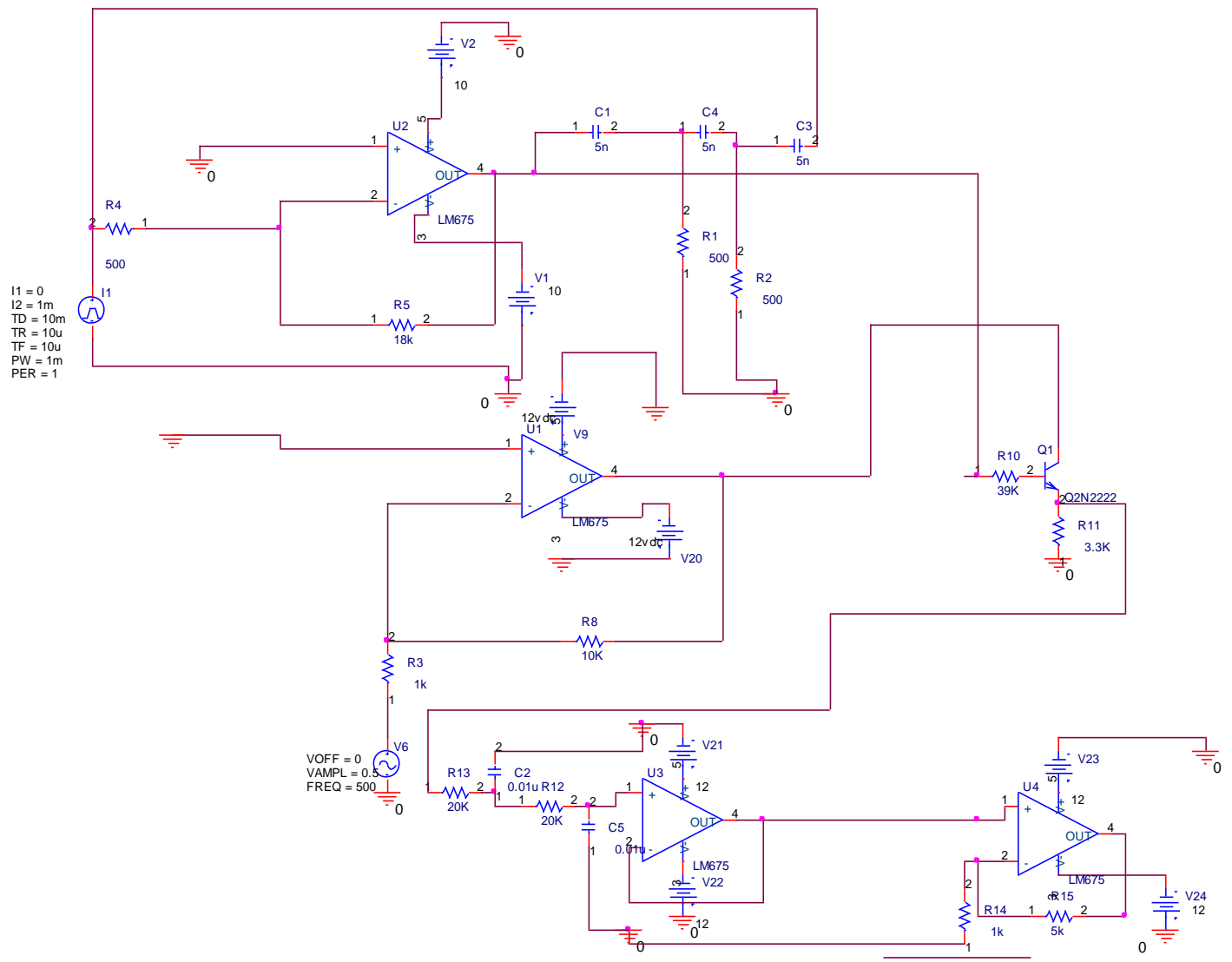

Fig 24: Voltage mode Communication System.

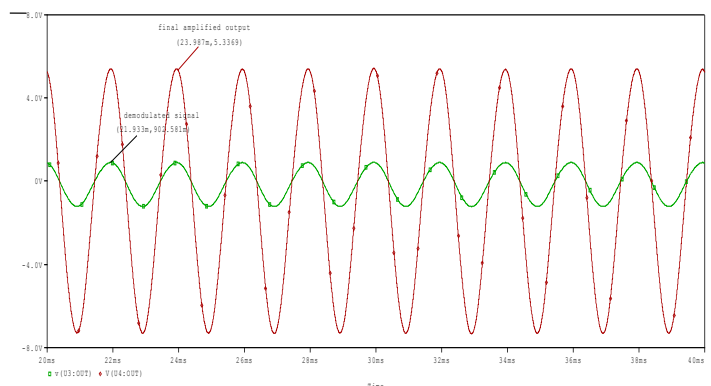

The above waveform is the Demodulated waveform (information signal) retrieved successfully from the system. The above waveform shows the Filter Output (Green) and the amplified version of Filtered Output (Red). Total Power Dissipation: 7.72E-01Watts

Fig 25: Output waveform of communication system in VM 


\subsection{Communication System in CM}

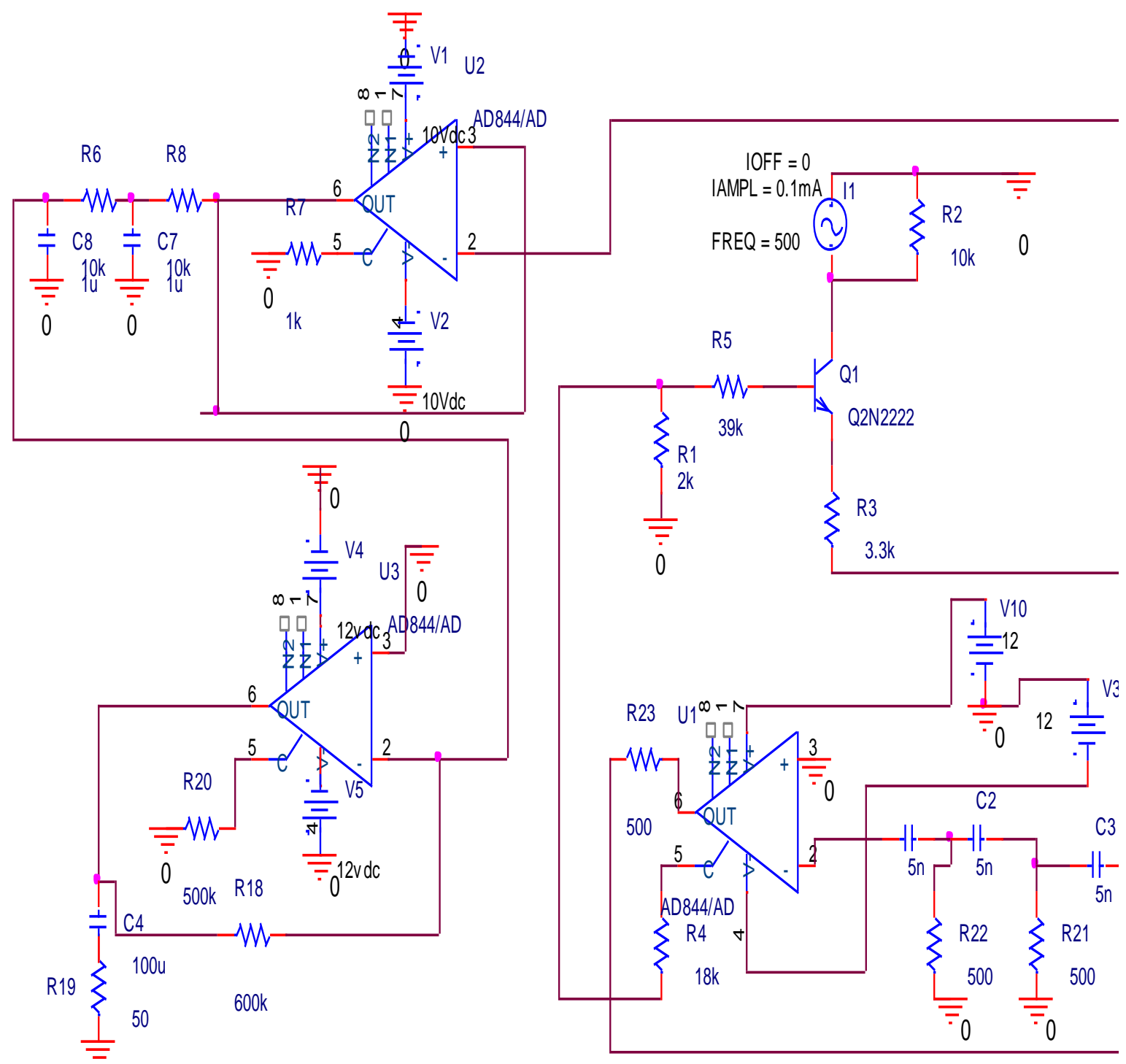

0

Fig 27: Current mode Communication System

This is the complete current mode communication system formed by combining the basic blocks designed in current mode.

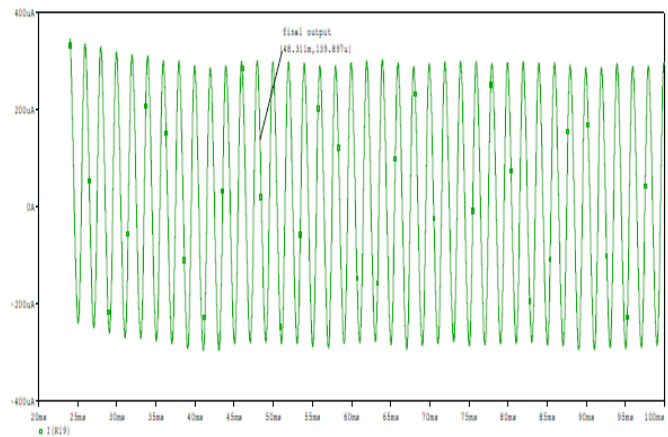

The above waveform is the Demodulated waveform (information signal) retrieved successfully from the system. Total Power Dissipation: 4.49E-01 Watts

\section{RESULTS}

Analysis is carried out by simulating individual circuits and complete system using PSPICE

Version 9.1 and the following results have been observed:-

Fig 28: Output Waveform 
INTERNATIONAL JOURNAL OF INNOVATIVE RESEARCH IN ELECTRICAL, ELECTRONICS, INSTRUMENTATION AND CONTROL ENGINEERING Vol. 3, Issue 3, March 2015

\begin{tabular}{|c|c|c|c|}
\hline & Voltage Mode & & Current Mode \\
\hline \multirow{5}{*}{$\begin{array}{l}\text { Inverting } \\
\text { Voltage Mode } \\
\text { Amplifier using } \\
\text { LM675: }\end{array}$} & a. I/P voltage: $0.5 \mathrm{~V}$ & \multirow{5}{*}{$\begin{array}{l}\text { Inverting Current } \\
\text { Mode Amplifier } \\
\text { using AD844: }\end{array}$} & a. I/P current: $0.1 \mathrm{~mA}$ \\
\hline & b. $\mathrm{O} / \mathrm{P}$ voltage: $5 \mathrm{~V}$ & & b. $\mathrm{O} / \mathrm{P}$ current: $0.5 \mathrm{~mA}$ \\
\hline & c. Gain: 10 & & c. Gain: 10 \\
\hline & $\begin{array}{l}\text { d. Frequency Range: } \\
300 \mathrm{kHz}\end{array}$ & & $\begin{array}{l}\text { d. Frequency Range: } \\
\text { Higher than } 300 \mathrm{kHz}\end{array}$ \\
\hline & $\begin{array}{l}\text { e. Total Power } \\
\text { Dissipation: } 2.09 \mathrm{E}-01 \\
\text { WATTS }\end{array}$ & & $\begin{array}{l}\text { e. Total Power } \\
\text { Dissipation: } 1.59 \mathrm{E}-01 \\
\text { WATTS }\end{array}$ \\
\hline \multirow[t]{3}{*}{$\begin{array}{l}\text { Voltage Mode } \\
\text { Oscillator }\end{array}$} & $\begin{array}{l}\text { a. Voltage Output: } 9 \\
\text { Vpp }\end{array}$ & \multirow[t]{3}{*}{$\begin{array}{l}\text { Current Mode } \\
\text { Oscillator }\end{array}$} & $\begin{array}{l}\text { a. Current Output: } 4.5 \\
\mathrm{~mA}\end{array}$ \\
\hline & b. Frequency: $20 \mathrm{kHz}$ & & b. Frequency: $20 \mathrm{kHz}$ \\
\hline & $\begin{array}{l}\text { c. Total Power } \\
\text { Dissipation: } 2.09 \mathrm{E}-01 \\
\text { WATTS }\end{array}$ & & $\begin{array}{l}\text { c. Total Power } \\
\text { Dissipation: } 1.59 \mathrm{E}-01 \\
\text { WATTS }\end{array}$ \\
\hline $\begin{array}{l}\text { Full Voltage } \\
\text { mode } \\
\text { communication } \\
\text { System }\end{array}$ & $\begin{array}{l}\text { a. Total Power } \\
\text { Dissipation: } 7.72 \mathrm{E}- \\
\text { 01Watts }\end{array}$ & $\begin{array}{l}\text { Full Current } \\
\text { mode } \\
\text { communication } \\
\text { System }\end{array}$ & $\begin{array}{l}\text { a. Total Power } \\
\text { Dissipation: } 4.49 \mathrm{E}-01 \\
\text { Watts }\end{array}$ \\
\hline
\end{tabular}

Table 1: Comparison of VM with CM

\section{CONCLUSION}

The various blocks of communication system are designed in voltage mode using Voltage Feedback Amplifier lm675 and successfully converted to their current mode equivalents using Current Feedback Amplifiers AD844. Full voltage mode and current mode systems have been developed successfully by combing the individual blocks designed above. Thus Current mode communication system could be developed by combining current mode circuits developed by converting their respective voltage mode circuits. The voltage mode circuit employing VFA suffers from miller effect which causes the gain to fall off at high frequencies, thus error increases as frequency increases because the effective loop gain decreases. In current mode circuit employing CFA doesn't nearly subject to miller effect resulting from stray capacitances as the VFA is. The absence of miller effect enables CFA's frequency response to hold up better than VFA's does. The Gain and bandwidth works better at higher frequencies of each other in the current mode whereas in voltage mode they are dependent on each other. The gain and bandwidth in voltage mode is interdependent. Thus Voltage mode incorporating VFA is constrained by Gain Bandwidth limitation because Gain of the circuit is incorporated with the closed loop Gain. On the other hand, current mode circuits using CFA's with the exceptions on RF, doesn't have this constraint. Thus it gives better performance at higher frequencies as compared to their voltage mode equivalents The ideal gain Equations are identical, but the applications are very different because Voltage mode Circuits are best suitable for lower frequency precision jobs while the Current mode applications are in the very high frequency realm. The Total power dissipation of individual circuits in voltage mode is greater than that in current mode as well as power dissipation of entire system in voltage mode is also greater than that of in current mode. Thus, from power consumption point of view to the current mode is better than the voltage mode.

\section{REFERENCES}

[1] P.V.Ananada Mohan "Current Mode VLSI analog Filters,Design and Application ",Springer Inrernational, Edition 2011.

[2] S. K. Mitra, "Analysis and Synthesis of Linear Active Networks", New York: John Wiley, 1969.

[3] S. S. Rajput, "Low-voltage current-mode analog circuit structures and their applications", PhD thesis., Indian Institute of Technology, Delhi., Aug. 2001.

[4] B. Wilson, "Recent developments in current conveyors and currentmode circuits," IEE Proc., vol. 137, (Pt. G.), no. 2, pp. 63-77, 1990.

[5] O. Ciçekoğlu, H. Kuntman, and S. Berk, "All-pass filters using a single current conveyor," Int. J. Electron., vol. 86, no. 8, pp. 947- 955, 1999.

[6] A. Toker, S. Özcan, H. Kuntman, and O. Ciçekoğlu, "Supplementary allpass sections with reduced number of passive elements using a single current conveyor", Int. J. Electron., vol. 88, no. 9, pp. 969-976, 2001.

[7] Y. Sugimoto, "A realization of a below-1-V operational and 30$\mathrm{MS} / \mathrm{s}$ sample-and-hold IC with a $56 \mathrm{~dB}$ signal-to-noise ratio by applying the current based circuit approach," IEEE Trans. Circuits Syst. I, Reg. Papers, vol. 51, no. 1, pp. 110-117, Jan. 2004

[8] A. Toker, S. Özcan, H. Kuntman,, and O. Çiçekoğlu, "Supplementary all-pass sections with reduced number of passive elements using a single current conveyor", Int. J. Electron., vol. 88, no. 9, pp. 969-976, 2001.

[9] Tejmal S Rathore1 and Uday P. Khot," Voltage Mode-to-Current Mode Transformation", IJET, ISSN : 0975-4024 Vol 4 No 5 OctNov 2012,pp- 349-363.

[10] B.P.Lathi,Zhi Ding, " Modern Digital and Analog Comunication Systems",OXFORD UNIVERSITY PRESS,First Edition 2004.

[11] Ron Mancini , "OP-AMPS for everyone" TEXAS INSTRUMENTS

[12] S. I. Liu, "Universal filter using two current feedback amplifiers," Electron. Lett., vol. 31, pp. 629-630, 1995.

[13] Electronic Design Software', OrCAD 10.0, Cadence Design Systems, Inc., USA, 2003 